\title{
Avaliação da Solarização do Solo para o Controle de Ralstonia solanacearum
}

\author{
Flávia R. A. Patrício ${ }^{1}$, Irene M. G. Almeida ${ }^{1}$, Amaury S. Santos ${ }^{1}$, Osvaldo Cabral' ${ }^{2}$ João Tessarioli Neto ${ }^{3}$, \\ Celso Sinigaglia ${ }^{1}$, Luís O. S. Beriam ${ }^{1} \&$ Júlio Rodrigues Neto ${ }^{1}$
}

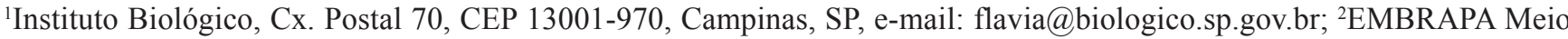

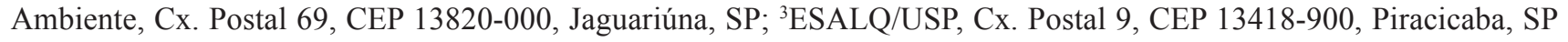

(Aceito para publicação em 28/06/2005)

Autor para correspondência: Flávia R. A. Patrício

PATRÍCIO, F.R.A., ALMEIDA, I.M.G., SANTOS, A.S., CABRAL, O., TESSARIOLI NETO, J., SINIGAGLIA, C., BERIAM, L.O.S. \& RODRIGUES NETO J. Avaliação da solarização do solo para o controle de Ralstonia solanacearum. Fitopatologia Brasileira 30:475-481. 2005.

\begin{abstract}
RESUMO
O presente trabalho avaliou o emprego da solarização como uma alternativa para o controle da murcha bacteriana, causada por Ralstonia solanacearum, em amostras de solo infestado com o patógeno, dispostas em bolsas de náilon e enterradas em parcelas solarizadas ou não. Dois experimentos foram instalados, um em Campinas (SP), de fevereiro a abril de 2001, e o outro em Piracicaba (SP), de dezembro de 2001 a janeiro de 2002. Os ensaios foram efetuados em delineamento inteiramente casualizado, esquema fatorial, com quatro repetições, tendo cada parcela 4 x $4 \mathrm{~m}$. Os fatores avaliados foram a solarização (com ou sem), efetuada com filme plástico transparente de $100 \mu \mathrm{m}$ de espessura, o período de tratamento (30 e 60 dias e 37 e 60 dias para o primeiro e o segundo experimentos, respectivamente) e a profundidade de colocação das amostras (10 e $20 \mathrm{~cm}$ ), fator verificado apenas no segundo ensaio. Após os períodos estipulados de solarização, o solo de cada bolsa foi colocado em vasos, para os quais foram transplantadas mudas de tomateiro (Lycopersicon esculentum). No solo não solarizado, em ambos os experimentos, 43 a 100\% dos tomateiros murcharam. No segundo experimento, 6 a $22 \%$ dos tomateiros murcharam no solo solarizado por 37 dias. Entretanto não foram detectadas plantas murchas nas parcelas solarizadas do primeiro experimento e no segundo ensaio nenhum tomateiro murchou solo solarizado por 60 dias, nas duas profundidades estudadas. Os resultados indicam que a solarização é uma técnica promissora para o controle de $R$. solanacearum.
\end{abstract}

Palavras-chave adicionais: murcha bacteriana, tomateiro.

\begin{abstract}
Soil solarization evaluation for the control of Ralstonia solanacearum

The use of soil solarization for the control of bacterial wilt, caused by Ralstonia solanacearum, was evaluated by burrowing nylon bags containing soil infested with the bacteria in plots solarized or not. Two experiments were carried out in Campinas (SP), from February to April/2001, and Piracicaba (SP), from December/2001 to February/2002. The experiments were set up in a completely randomized factorial design, with four replications, in 4 x 4 meter plots. The factors evaluated were soil solarization with a transparent plastic film $100 \mu \mathrm{m}$ thick, period of treatment (30 and 60 days and 37 and 60 days for the first and second experiments, respectively) and, only for the second experiment, soil depth (10 and $20 \mathrm{~cm}$ ). The soil of each nylon bag collected after the previously established solarization periods, was placed in pots where tomato (Lycopersicon esculentum) seedlings were transplanted. In the non-solarized soil, in both experiments, 43 to $100 \%$ of the tomato plants wilted. In the second experiment, 6 to $22 \%$ of the plants grown on the soil solarized for 37 days wilted. No wilted tomato plants were observed in the solarized plots of the first experiment nor in the soil solarized for 60 days, in both soil depths, of the second experiment. The results obtained indicate that soil solarization has potential for the control of $R$. solanacearum.
\end{abstract}

Additional keywords: bacterial wilt, tomato, Lycopersicon esculentum.

\section{INTRODUÇÃO}

A murcha bacteriana, causada por Ralstonia solanacearum (Smith 1896) Yabuuchi et al. 1995 (Yabuuchi et al., 1995), é uma das mais importantes doenças de plantas do mundo. A bactéria sobrevive no solo por longos períodos e encontra-se amplamente distribuída em regiões tropicais e subtropicais, podendo atacar um grande número de espécies cultivadas. A doença ocorre em todo Brasil, inclusive em áreas recém-desmatadas, tendo sido descrita em diversas solanáceas, especialmente batata (Solanum tuberosum L.), tomateiro (Lycopersicon esculentum Mill.), pimentão (Capsicum annuum L.), berinjela (Solanum melongena L.) e fumo (Nicotiana tabacum L.). A bactéria infeta, também, espécies cultivadas de outras famílias botânicas, entre as quais: as musáceas banana (Musa spp.) e helicônia (Heliconia spp.); e as cucurbitáceas pepino (Cucumis sativus L.) e abóbora-de-moita (Cucurbita pepo L.) (Hayward, 1994;

Fitopatol. bras. 30(5), set - out 2005 
Parente et al., 1998; Sinigaglia et al., 2001). O patógeno apresenta grande diversidade, caracterizada pela ocorrência de raças com especificidade por hospedeiros, e de biovares, classificados conforme a habilidade em utilizar determinados açúcares e álcoois (Hayward, 1991). Apresenta ainda características especiais de sobrevivência no solo e na rizosfera de inúmeras espécies não hopedeiras, o que dificulta ainda mais o seu controle (Takatsu \& Lopes, 1997). Considerando a complexidade da murcha bacteriana, Takatsu \& Lopes (1997) sugerem que o controle da doença seja abordado dentro de um contexto de manejo integrado, com a aplicação de diversas medidas como a rotação de culturas, o plantio em áreas indenes, a resistência genética, o manejo da água e também a solarização.

A solarização, técnica desenvolvida para a desinfestação de solos e substratos antes do plantio (Katan et al., 1976), consiste na colocação de um filme plástico transparente sobre o solo úmido, visando aumentar sua temperatura, durante o período do ano de maior radiação solar (Katan \& De Vay, 1991; Souza, 1994). O aquecimento do solo ocorre em ciclos repetidos diariamente. As temperaturas alcançadas durante o processo são letais nas camadas superficiais e subletais nas mais profundas a muitos fitopatógenos, pragas e plantas daninhas, e podem provocar alterações biológicas, químicas e físicas nos solos, resultando, freqüentemente, em aumento de produção das culturas (Katan \& De Vay, 1991; Souza, 1994; Ghini et al., 2003). Embora inúmeros patógenos habitantes do solo sejam controlados pela solarização, poucos trabalhos avaliaram o efeito dessa técnica sobre bactérias fitopatogênicas, especialmente $R$. solanacearum. Estudos realizados na Flórida, EUA, por Chelemi \& Olson (1994), mostraram que a solarização reduziu a população dessa bactéria apenas nas camadas mais superficiais do solo. Visando incorporar a solarização às práticas de manejo da cultura do tomateiro, outros experimentos, realizados também na Flórida, revelaram resultados positivos para o controle de vários fitopatógenos habitantes do solo, mas foram pouco consistentes para a murcha bacteriana (Chelemi et al., 1997). Na Índia, Kumar \& Sood (2001) obtiveram redução parcial na incidência da murcha bacteriana após a solarização do solo. No Japão, a solarização é considerada pouco efetiva para o controle da murcha bacteriana em casas de vegetação (Horiuki, 1991).

No Brasil, a solarização tem se mostrado eficiente para o controle de vários fungos fitopatogênicos veiculados pelo solo como Pythium sp., Sclerotium cepivorum Berk, Verticillium dahliae Kleb, Sclerotinia minor Jagger e Rhizoctonia solani Kühn, nas culturas de crisântemo (Chrysanthemum spp), alho (Allium sativum L.), berinjela, feijoeiro (Phaseolus vulgaris L.) e alface (Lactuca sativa L.), respectivamente (Ghini et al., 1992; Cunha et al., 1993; Bettiol et al., 1994; Ghini et al., 1997; Sinigaglia et al., 2001). Para as doenças bacterianas, Cavalcante et al. (1999) obtiveram o controle de $R$. solanacearum na cultura da pimenta longa (Piper hispidinervium C.DC), em experimento realizado em Rondônia.
Considerando que a murcha bacteriana causa prejuízos consideráveis em inúmeras culturas e que seu controle ainda é um desafio, o presente trabalho foi realizado visando avaliar o potencial da solarização para o controle dessa doença.

\section{MATERIAL E MÉTODOS}

Foi preparada uma suspensão bacteriana a partir de uma linhagem de $R$. solanacearum (IBSBF 32) isolada de tomateiro, pertencente à raça 1 , biovar $\mathrm{I}$, e depositada na Coleção de Culturas IBSBF do Instituto Biológico. A bactéria foi cultivada em meio de Kelman (Kelman, 1954), para identificar as colônias virulentas, as quais foram multiplicadas em meio nutriente-agar e usadas no preparo da suspensão.

Em seguida, bolsas de náilon receberam 11 de terra (Latossolo roxo) peneirada e seca à sombra, previamente misturada a $100 \mathrm{ml}$ da suspensão aquosa de $R$. solanacearum, com concentração aproximada de $2 \times 10^{6} \mathrm{ufc} / \mathrm{ml}$. Para o tratamento controle também foram preparadas bolsas contendo terra misturada a apenas $100 \mathrm{ml}$ de água destilada. Em seguida, foram preparadas amostras constituídas por duas bolsas de náilon amarradas a um cordão plástico e a uma etiqueta. Essas amostras foram dispostas de maneira casualizada sobre as áreas a serem solarizadas ou não, mantendo-se uma distância mínima de $40 \mathrm{~cm}$ das bordas. As amostras contendo as bolsas foram enterradas a 10 e a 10 e $20 \mathrm{~cm}$ de profundidade, para o primeiro e segundo experimentos, respectivamente.

O primeiro experimento foi realizado em área pertencente ao Instituto Biológico, em Campinas-SP (latitude $22^{\circ}$ $54^{\prime}$ ' e longitude $47^{\circ} 05^{\prime}$ ), no período de 22 de fevereiro a 24 de abril de 2001. O experimento foi instalado em delineamento inteiramente casualizado com quatro repetições, em esquema fatorial, $2 \times 2$, sendo o fator 1 , solarização (com e sem) e o fator 2 , período de solarização (30 e 60 dias). O segundo experimento foi realizado em área experimental do Departamento de Produção Vegetal, da ESALQ-USP, em Piracicaba-SP (latitude $22^{\circ} 42^{\prime}$ e longitude $47^{\circ} 38^{\prime}$ ), no período de 22 de dezembro de 2001 a 24 de fevereiro de 2002. O experimento foi instalado em delineamento inteiramente casualizado com quatro repetições, em esquema fatorial $2 \times 2 \times 2$, sendo o fator 1, solarização (com e sem), o fator 2, período de solarização ( 37 e 60 dias) e o fator 3, a profundidade de colocação das amostras de solo infestado com a bactéria $(10$ e $20 \mathrm{~cm})$.

Nos dois experimentos, foi colocado um filme plástico transparente (com aditivo estabilizador de luz ultravioleta e $100 \mu \mathrm{m}$ de espessura, semelhante aos utilizados em casas de vegetação) sobre o solo previamente umedecido até próximo à capacidade de campo, cobrindo toda a parcela a ser solarizada. As bordas foram enterradas para evitar ventilação e manter a temperatura em seu interior. Todas as parcelas não solarizadas foram igualmente mantidas umedecidas após a instalação e durante a condução dos experimentos. Cada 
parcela, solarizada ou não, apresentou as dimensões de 4 x 4 $\mathrm{m}$. As temperaturas do solo foram registradas no segundo experimento com termômetros de solo acoplados a um coletor de dados (Campbell CR-10X), instalados a 10 e $20 \mathrm{~cm}$ de profundidade, nas parcelas solarizadas ou não. Os dados climáticos, temperatura máxima e mínima do ar e a precipitação, foram fornecidos por estações climatológicas (UNICAMP e ESALQ-USP).

Após cada período de solarização, foi coletada uma amostra de cada parcela. As amostras retiradas nos primeiros períodos, 30 e 37 dias após o início do primeiro e segundo experimentos, respectivamente, permaneceram em ambiente de laboratório até que se completasse o tempo do segundo período (60 dias). O solo de cada amostra (2 1 de solo) foi colocado em vasos plásticos de $15 \mathrm{~cm}$ de altura por $18 \mathrm{~cm}$ de diâmetro. Em seguida, para cada vaso foram transplantadas cinco mudas de tomateiro com aproximadamente 40 dias, previamente formadas em substrato padronizado, contendo duas folhas verdadeiras. Antes do transplantio as raízes das mudas foram cortadas nas pontas para favorecer a penetração da bactéria. Os tomateiros foram observados por 40 dias, anotando-se o número de plantas murchas. Após esse período, outras cinco mudas de tomateiro, preparadas nas mesmas condições, foram transplantadas para cada vaso, sendo observada a ocorrência ou não de murcha por mais 30 dias. No primeiro experimento foi utilizada somente a cultivar Santa Clara e no segundo, inicialmente foi transplantada a cultivar Agrocica 94 e, em seguida, a cultivar Ângela. Durante a condução dos experimentos, plantas com sintomas de murcha foram examinadas e, caso constatada exsudação bacteriana do tecido, foram feitos reisolamentos para confirmação da presença de $R$. solanacearum. Mudas de tomateiro também foram transplantadas para vasos com o solo que recebeu apenas água destilada, não infestado pela bactéria.

\section{RESULTADOS E DISCUSSÃO}

No primeiro experimento, não foram verificados sintomas de murcha nos tomateiros da cultivar Santa Clara transplantados para os solos solarizados por 30 e 60 dias, mas todas as plantas transplantadas para o solo não solarizado murcharam (Tabela 1). Nenhum tomateiro das amostras controle apresentou sintomas da doença. As mudas utilizadas no segundo transplantio, da mesma cultivar, apresentaram comportamento semelhante.

No segundo experimento, após 37 dias de solarização ainda foram observadas plantas com sintomas de murcha nos solos solarizados nas duas profundidades avaliadas, mas após 60 dias nenhum tomateiro murchou, indicando que o tratamento, assim como no ensaio anterior, promoveu o controle do patógeno (Tabela 1). Para a cultivar Agrocica 94, apenas o fator solarização foi significativo, não havendo interação entre os fatores (Tabela 2). Para a cultivar Ângela, transplantada em seguida, houve interação entre solarização e período de tratamento, provavelmente porque essa cultivar se mostrou mais sensível à doença (Tabela 1). Para ambas as cultivares não houve efeito significativo da profundidade de colocação das amostras (Tabela 2). Assim como no experimento anterior, nenhuma planta dos vasos do controle murchou.

Nas amostras de solo enterradas nas áreas não solarizadas, os tomateiros das cultivares Ângela e Santa Clara foram mais afetados pela doença, os sintomas tiveram início em torno de quatro a cinco dias após o transplantio, e quase todas as plantas estavam mortas até dez dias depois (Tabela 1). Os tomateiros da cultivar Agrocica 94, entretanto, começaram a murchar somente dez dias após o transplantio e alguns sobreviveram até 40 dias depois, embora não tenham havido variações muito significativas nas temperaturas do ambiente da casa de vegetação durante a condução dos testes biológicos.

No presente trabalho, as cultivares Ângela e Santa Clara, de hábito indeterminado de crescimento e pertencentes ao grupo Santa Cruz, comportaram-se como muito suscetíveis à murcha bacteriana. A cultivar Santa Clara tem sido utilizada como planta indicadora para a detecção de $R$. solanacearum no solo (Tavares et al., 2000) e como padrão de suscetibilidade em programas de seleção para resistência à murcha (Lima Neto et al., 2001). Embora as cultivares comerciais de tomateiro sejam consideradas suscetíveis à murcha bacteriana (Lopes \& Quezado-Soares, 2000), no presente trabalho a cultivar Agrocica 94, de hábito determinado de crescimento e indicada para o cultivo rasteiro, foi menos afetada pela doença.

No primeiro experimento, 30 dias foram suficientes para promover o controle do patógeno, mas no segundo, alguns tomateiros murcharam nos solos solarizados por 37 dias, em ambas as profundidades avaliadas, indicando que parte da população bacteriana ainda se encontrava viável (Tabela 1). Esse fato deve ter ocorrido porque 18 dias foram chuvosos nesse período (Figura 1b), mas houve precipitação em apenas seis dos primeiros 30 dias do experimento anterior (Figura 1a). A ocorrência de chuvas em dias consecutivos, inclusive, motivou a prorrogação da retirada das amostras de solo, inicialmente prevista para 30 dias de tratamento. É interessante observar que nos dias chuvosos a elevação na temperatura do solo solarizado é pequena (Figura 1d), comprometendo a eficiência do tratamento, podendo-se inferir que, caso persistam dias com chuvas, o período de tratamento deva ser prolongado.

Os dados do presente trabalho, assim como os do experimento realizado em Rondônia por Cavalcante et al. (1999), indicam que a solarização poderá ser promissora como método de controle de $R$. solanacearum. Esses resultados diferem dos obtidos em experimentos de solarização realizados por Chelemi \& Olson (1994) e Chelemi et al. (1997) na Flórida, por Horiuki et al. (1991) no Japão, e por Kumar \& Sood (2001) na Índia.

Em três experimentos realizados em diferentes locais por Chelemi \& Olson (1994), a solarização reduziu significativamente a população de $R$. solanacearum na 
profundidade de $5 \mathrm{~cm}$. No entanto, nas demais profundidades avaliadas $(15,25$ e $30 \mathrm{~cm})$, apenas em um local ocorreu redução na sobrevivência da bactéria, a $15 \mathrm{~cm}$ de profundidade. Nesse experimento foram registradas nas parcelas solarizadas, durante a solarização, $111 \mathrm{~h}$ com temperaturas do solo acima de $40^{\circ} \mathrm{C}$ a $5 \mathrm{~cm}$ de profundidade, mas apenas 94 e $51 \mathrm{~h}$ nos demais ensaios. No presente trabalho, após 60 dias de solarização, foram registradas 405 e $142 \mathrm{~h}$ de temperaturas acima de $40{ }^{\circ} \mathrm{C}$, a 10 e a $20 \mathrm{~cm}$ de profundidade, respectivamente (Tabela 3 ), valores muito superiores aos obtidos na Flórida, sendo essa a possível explicação para os resultados conflituosos.

Em Piracicaba as temperaturas médias registradas no solo solarizado, considerando todo o período do tratamento, atingiram até $44{ }^{\circ} \mathrm{C}$ (Figura 1c), e as máximas foram 12 a 15 ${ }^{\circ} \mathrm{C}$ superiores (Figura 1d) respectivamente, para 10 e $20 \mathrm{~cm}$ de profundidade, que as verificadas nas parcelas não solarizadas. Essas elevadas temperaturas possivelmente foram responsáveis pelo controle do patógeno verificado após a solarização. No experimento realizado em Campinas, as temperaturas do solo provavelmente foram elevadas, embora não tenham sido registradas, já que as temperaturas médias e máximas do ambiente (Figura 1a) foram semelhantes às obtidas em Piracicaba (Figura 1b) e o patógeno também foi controlado pela solarização.

A temperatura máxima de $50,5{ }^{\circ} \mathrm{C}$ a $10 \mathrm{~cm}$ de profundidade, atingida no presente trabalho (Figura 1d), foi superior às obtidas a $5 \mathrm{~cm}$ de profundidade por Chelemi \& Olson (1994) na Flórida $\left(47,9{ }^{\circ} \mathrm{C}\right.$ em dois locais e $49,5^{\circ} \mathrm{C}$ em outro, a $5 \mathrm{~cm}$ de profundidade) e às registradas na Índia, por Kumar \& Sood (2001), de 40,1 e 40,6 ${ }^{\circ} \mathrm{C}$, a $5 \mathrm{~cm}$ de profundidade. Nos experimentos realizados por Chelemi et al. (1997), em dois anos consecutivos, as temperaturas máximas dos solos solarizados foram de 49,2 e $48,7^{\circ} \mathrm{C}$ a 10 $\mathrm{cm}$ de profundidade, valores próximos aos registrados em Piracicaba, porém os autores não observaram o controle do patógeno. Como nesses experimentos a solarização foi efetuada apenas em canteiros, sobre os quais foram posteriormente cultivados tomateiros, os autores atribuíram tais resultados a uma possível reinfestação das plantas pelo patógeno presente no solo que ficou entre os canteiros e não foi solarizado.

Katan (1996) comenta que os dados obtidos em experimentos de solarização que utilizam amostras de solo

TABELA 1 - Incidência de murcha bacteriana, causada por Ralstonia solanacearum, em tomateiros (Lycopersicon esculentum) transplantados para solos solarizado e não solarizado, a 10 e a $20 \mathrm{~cm}$ de profundidade, em experimentos realizados em Campinas, SP, no período de 22 de fevereiro a 23 de abril de 2001, e em Piracicaba, SP, no período de 20 de dezembro de 2001 a 21 de fevereiro de 2002

\begin{tabular}{|c|c|c|c|c|c|c|c|}
\hline \multirow{4}{*}{ Fator } & \multirow{4}{*}{ Profundidade } & \multicolumn{6}{|c|}{ Incidência de murcha bacteriana $^{1}$} \\
\hline & & \multirow{2}{*}{\multicolumn{2}{|c|}{$\begin{array}{c}2001 \\
\text { cv. Santa Clara }\end{array}$}} & \multicolumn{4}{|c|}{$2001 / 2002$} \\
\hline & & & & \multicolumn{2}{|c|}{ cv. Agrocica 94} & \multicolumn{2}{|c|}{ cv. Ângela } \\
\hline & & 30 dias & 60 dias & 37 dias & 60 dias & 37 dias & 60 dias \\
\hline \multirow[t]{2}{*}{ Solo solarizado } & $10 \mathrm{~cm}$ & 0,0 & 0,0 & 2,3 & 0,0 & 18,0 & 0,0 \\
\hline & $20 \mathrm{~cm}$ & - & - & 12,0 & 0,0 & 19,9 & 0,0 \\
\hline \multirow[t]{2}{*}{ Solo não solarizado } & $10 \mathrm{~cm}$ & 100,0 & 100,0 & 43,2 & 72,6 & 99,9 & 99,9 \\
\hline & $20 \mathrm{~cm}$ & - & - & 47,2 & 63,8 & 99,9 & 99,9 \\
\hline \multicolumn{2}{|c|}{ Coeficiente de variação (\%) } & \multicolumn{2}{|c|}{ Sem variância } & \multicolumn{2}{|c|}{55,0} & \multicolumn{2}{|c|}{29,0} \\
\hline
\end{tabular}

'Avaliações realizadas 5 a 40 dias após o transplantio. Em 2002 a variedade Agrocica foi transplantada logo após a solarização e a variedade Ângela 40 dias depois, nos mesmos solos.

TABELA 2 - Análise de variância para os efeitos solarização, período, profundidade e interações entre esses fatores sobre a incidência de murcha bacteriana em tomateiros (Lycopersicon esculentum) das cultivares Agrocica 94 e Ângela

\begin{tabular}{lcc}
\hline \hline & \multicolumn{2}{c}{$\begin{array}{c}\text { Probabilidade de F para incidência de murcha bacteriana, causada por } \\
\text { Ralstonia solanacearum, em tomateiros }\end{array}$} \\
\cline { 2 - 3 } & \multicolumn{2}{c}{ Cultivares } \\
\cline { 2 - 3 } & Agrocica 94 & Ângela \\
\hline Solarização & $<0,001^{2}$ & $<0,001^{2}$ \\
Período & 0,836 & $0,008^{2}$ \\
Profundidade & 0,656 & 0,933 \\
Solarizacao x período & 0,067 & $0,008{ }^{2}$ \\
Solarizacação x profundidade & 0,571 & 0,933 \\
Período x profundidade & 0,532 & 0,933 \\
\hline Coeficiente de variação (\%) & 55,0 & 29,0 \\
\hline${ }^{1}$ Solarização efetuada de 22 de dezembro de 2001 a 24 de fevereiro de 2002, em Piracicaba, SP. \\
${ }^{2}$ Probabilidade de $\mathrm{F}<0,05$ considerada significativa.
\end{tabular}


TABELA 3 - Número de horas com temperaturas acima de 30, 35, 40 e $45^{\circ} \mathrm{C}$, em solos solarizado e não solarizado, em experimento de solarização, realizado de 22 de dezembro de 2001 a 24 de fevereiro de 2002 em Piracicaba, SP

\begin{tabular}{|c|c|c|c|c|c|c|}
\hline \multirow{2}{*}{ Tratamento } & \multirow{2}{*}{$\begin{array}{l}\text { Profundidade } \\
\text { (cm) }\end{array}$} & \multirow{2}{*}{$\begin{array}{c}\text { Período } \\
\text { (dias) }\end{array}$} & \multicolumn{4}{|c|}{ Número de horas com temperaturas do solo acima de } \\
\hline & & & $30{ }^{\circ} \mathrm{C}$ & $35^{\circ} \mathrm{C}$ & $40{ }^{\circ} \mathrm{C}$ & $45^{\circ} \mathrm{C}$ \\
\hline \multirow[t]{2}{*}{ Solo solarizado } & 10 & 37 & 888 & 549 & 194 & 53 \\
\hline & 20 & 37 & 899 & 381 & 30 & 0 \\
\hline \multirow[t]{2}{*}{ Solo não solarizado } & 10 & 37 & 90 & 0 & 0 & 0 \\
\hline & 20 & 37 & 22 & 0 & 0 & 0 \\
\hline \multirow[t]{2}{*}{ Solo solarizado } & 10 & 60 & 1438 & 999 & 405 & 129 \\
\hline & 20 & 60 & 1451 & 872 & 142 & 0 \\
\hline \multirow[t]{2}{*}{ Solo não solarizado } & 10 & 60 & 127 & 0 & 0 & 0 \\
\hline & 20 & 60 & 24 & 0 & 0 & 0 \\
\hline
\end{tabular}
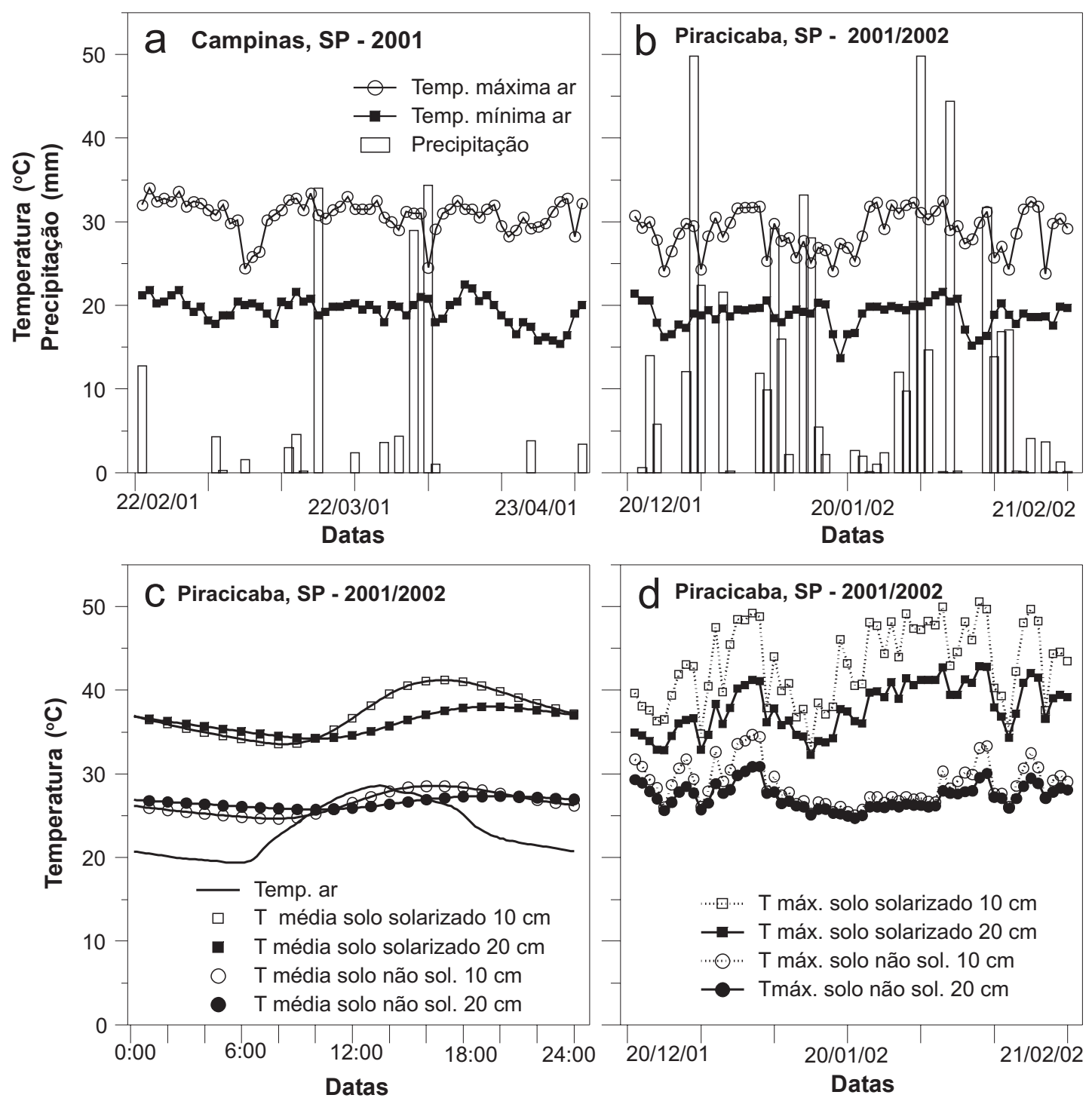

FIG. 1 - a) Temperaturas máxima e mínima do ar e precipitação registradas durante o experimento de solarização realizado em Campinas, SP (fevereiro-abril/2001); b) temperaturas máxima e mínima do ar e precipitação registradas durante o experimento de solarização realizado em Piracicaba, SP (dezembro/2001 a janeiro/2002); c) temperaturas médias do ar e dos solos solarizado e não solarizado, durante experimento realizado em Piracicaba, SP (dezembro/2001 a janeiro/2002), d) temperaturas máximas dos solos solarizado e não solarizado, durante experimento realizado em Piracicaba, SP (dezembro/ 2001 a janeiro/2002). 
infestadas ou contendo propágulos de patógenos, dispostas em bolsas de náilon e enterradas em várias profundidades, precisam ser interpretados com cuidado, mas podem fornecer uma primeira avaliação com relação ao período do ano ideal e ao tempo necessário para o tratamento, quanto à sensibilidade do patógeno à temperatura e também sobre a profundidade em que o patógeno é controlado. $\mathrm{O}$ presente trabalho mostrou resultados promissores; porém, é preciso considerar que em condições naturais pode não haver a mesma eficiência de controle.

Sabe-se que a bactéria pode ser encontrada viável a até $1 \mathrm{~m}$ de profundidade (Takatsu \& Lopes, 1997) e que sobrevive por longos períodos nas camadas mais profundas do solo, sendo favorecida pelas temperaturas amenas e baixa atividade microbiana que prevalecem nessas condições (Hayward, 1991). Após a solarização, existe a possibilidade de a bactéria aflorar por capilaridade e reinfestar as camadas mais superficiais do solo.

A eficiência da técnica também pode ser comprometida porque o sistema radicular do tomateiro atinge até $1,25 \mathrm{~m}$ de profundidade, embora $70 \%$ se concentre entre $0 \mathrm{e}$ $20 \mathrm{~cm}$ e $95 \%$ em até $50 \mathrm{~cm}$ de profundidade (FAO, 2003). Como a doença ocorre no campo a partir do florescimento, pode ser que nesse estádio as raízes já tenham alcançado as camadas de solo em que a bactéria se encontra viável.

Por outro lado, durante o tratamento ocorre fluxo ascendente de água no solo, que evapora e recondensa na superfície inferior do plástico (Chen et al., 1991), e que pode trazer o inóculo (ou parte dele) retido nas camadas mais profundas, para as mais superficiais, expondo-o às elevadas temperaturas atingidas durante a solarização. Alterações na estrutura física do solo, com redução significativa na compactação, causadas em parte por esse fluxo ascendente de água, podem chegar a até 2,0 $\mathrm{m}$ de profundidade, como demonstrado por Ghini et al. (2003).

A bactéria também sobrevive associada à rizosfera de diversas plantas daninhas e outras não hospedeiras, o que dificulta e muitas vezes compromete a eficiência da rotação de culturas para o controle da murcha bacteriana (Hayward, 1991; Hartman \& Elphinstone, 1994; Takatsu \& Lopes, 1997). Nos presentes experimentos não foi observada a presença de plantas daninhas nas parcelas solarizadas durante e após o tratamento, fato considerado por Katan (1996) como indicativo da efetividade da técnica. Em experimentos realizados no Brasil, Singaglia et al. (2001) e Barros et al. (2004) constataram severa redução na população de plantas daninhas até vários meses após o emprego da técnica, o que pode dificultar ainda mais a sobrevivência da bactéria e favorecer a eficiência da solarização para o controle do patógeno.

Os resultados promissores do presente trabalho sugerem que estudos adicionais em áreas naturalmente infestadas merecem ser realizados, especialmente em locais de elevado valor econômico e intensivamente cultivados. Entretanto, por causa da complexidade da murcha bacteriana, pode ser necessária a combinação da solarização com outros métodos que demonstraram potencial, mas que não ofereceram controle consistente da doença quando aplicados isoladamente, como a resistência de cultivares (Prior et al., 1994), a fumigação com cloropicrina, a adição de matéria orgânica no solo e o controle biológico (Hartman \& Elphinstone, 1994).

\section{REFERÊNCIAS BIBLIOGRÁFICAS}

BARROS, B.C., PATRÍCIO, F.R.A., LOPES, M.E.B.M., FREITAS, S.S., SINIGAGLIA, C., MALAVOLTA, V.M.A., TESSARIOLI NETO, J. \& GHINI, R. Solarização do solo com filmes plásticos com e sem aditivo estabilizador de luz ultra violeta. Horticultura Brasileira 22:253-259. 2004.

BETTIOL, W., GHINI, R. \& GALVÃO, J.A.H. Solarização do solo para o controle de Pythium e plantas daninhas em cultura do crisântemo. Scientia Agricola 51:459-462. 1994.

CAVALCANTE, M.J.B., RITZINGER, C.H.S.P. \& BERGO, C. Uso da solarização do solo no controle da murcha bacteriana (Ralstonia solanacearum) no cultivo de pimenta longa (Piper hispidinervium) em Vila Extrema-RO. Fitopatologia Brasileira 24:248. 1999. (Resumo)

CHELEMI, D.O. \& OLSON, S.M. Effects of soil solarization and fumigation on survival of soilborne pathogens of tomato in Northern Florida. Plant Disease 78:1167-1172. 1994.

CHELEMI, D.O., OLSON, S.M., MITCHELL, D.J., SECKER, I. \& McSORLEY, R. Adaptation of soil solarization to the integrated management of soilborne pests of tomato under humid conditions. Phytopathology 87:250-258. 1997.

CHEN, Y., GAMLIEL, A., STAPleton, J.J. \& AVIAD, T. Chemical, physical and microbial changes related to plant growth in disinfested soils. In: Katan, J. \& DeVay, J.E. (Eds.) Soil solarization. Boca Raton. CRC Press. 1991. pp.24-37.

CUNHA, M.G. da, ZAMBOLIM, L., VALE, F.X.R. do, CHAVES, G.M. \& ALVES, H. Efeito da solarização com filmes de polietileno transparente, preto ou branco no controle da podridão branca do alho (Sclerotium cepivorum). Fitopatologia Brasileira 18:199-205. 1993.

FAO. El cultivo protegido en clima mediterráneo. Estudios FAO: Producción y protección vegetal. Roma. Organización de las naciones unidas para la Agricultura e la Alimentacion. 2002.

GHINI, R., BETTIOL, W. \& CALDARI JR., P. Solarização do solo para o controle de Sclerotium rolfsii em feijoeiro. Summa Phytopathologica 23:143-145. 1997.

GHINI, R., BETTIOL, W. \& SOUZA, N.L. Solarização do solo para o controle de Verticillium dahliae em berinjela. Fitopatologia Brasileira 17:384-388. 1992.

GHINI, R., PATRÍCIO, F.R.A., SOUZA, M.D., SINIGAGLIA, C., BARROS, B.C., LOPES, M.E.B.M., TESSARIOLI NETO, J. \& CANTARELLA, H. Efeito da solarização sobre as propriedades físicas, químicas e biológicas de solos. Revista Brasileira de Ciência do Solo 27:71-79. 2003.

HARTMAN, G.L. \& ELPHINSTONE, J.G. Advances in the control of Pseudomonas solanacearum Race 1 in major food crops. In: Hayward, A.C. \& Hartman, G.L. (Eds.) Bacterial wilt. The disease and its causative agent, Pseudomonas solanacearum. Walingford. CAB International. 1994. pp.157-177. 
HAYWARD, A.C. Biology and epidemiology of bacterial wilt caused by Pseudomonas solanacearum. Annual Review of Phytopathology 29:65-87. 1991.

HAYWARD, A.C. The hosts of Pseudomonas solanacearum. In: Hayward, A.C. \& Hartman, G.L. (Eds.) Bacterial wilt. The disease and its causative agent, Pseudomonas solanacearum. Walingford. CAB International. 1994. pp.09-23.

KATAN, J. \& DeVAY, J.E. Soil solarization; historical perspectives, principles and uses. In: Katan, J. \& DeVay, J.E. (Eds.) Soil solarization. Boca Raton. CRC Press. 1991. pp.24-37.

KATAN, J. Soil solarization: integrated control aspects. In: Hall, R. (Ed.) Principles and Practices of Managing Soilborne Plant Pathogens. St. Paul. APS Press, The American Phytopathological Society. 1996. pp.213-236.

KATAN, J., GREENBERGER, A., ALON, H. \& GRINSTEIN, A. Solar heating by polyethylene mulching for the control of diseases caused by soil-borne pathogens. Phytopathology 66:683-688. 1976.

KELMAN, A. The relationship of pathogenicity in Pseudomonas solanacearum to colony appearance on a tetrazolium medium. Phytopathology 44:693-695. 1954.

KUMAR, P. \& SOOD, A.K. Integration of antagonistic rhizobacteria and soil solarization for the management of bacterial wilt of tomato caused by Ralstonia solanacearum. Indian Phytopathology 54:1215. 2001 .

LIMANETO, A.F., SOUZA, R.M., SILVEIRA, M.A., NOGUEIRA, S.R., ANDRÉ, C.M.G. \& POZZA, E.A. Reação de genótipos de tomateiro à murcha bacteriana em solo naturalmente infestado. Fitopatologia Brasileira 26:289. 2001. (Resumo)

LOPES, C.A. \& QUEZADO-SOARES, A.M. Doenças causadas por bactérias em tomate. In: Zambolim, L., Ribeiro do Vale, F.X. \& Costa, H. (Eds.) Controle de doenças de plantas - hortaliças. Viçosa. UFV. 2000. v.2, pp.757-799.
PARENTE, P.M.G., TAKATSU, A. \& LOPES, C.A. Ocorrência de Pseudomonas solanacearum em pepino. Horticultura Brasileira 6:26-27. 1988.

PRIOR, P., GRIMAULT, V. \& SCHMIDT, J. Resistance to bacterial wilt (Pseudomonas solanacearum) in tomato: present status and prospects. In: Hayward, A.C. \& Hartman, G.L. (Eds.) Bacterial wilt. The disease and its causative agent, Pseudomonas solanacearum. Walingford. CAB International. 1994. pp.209-223.

SINIGAGLIA, C., LOPES, M.E.B.M., ALMEIDA, I.M.G. \& RODRIGUES NETO, J. Bacterial wilt of summer squash (Cucurbita pepo) caused by Ralstonia solanacearum in the State of São Paulo, Brazil. Summa Phytopahtologica 27:251-253. 2001.

SINIGAGLIA, C., PATRÍCIO, F.R.A., GHINI, R., MALAVOLTA, V.M.A., TESSARIOLI, J. \& FREITAS, S.S. Controle de Sclerotinia minor, Rhizoctonia solani e plantas daninhas pela solarização do solo e sua integração com controle químico. Summa Phytopathologica 27:229-235. 2001.

SOUZA, N.L. Solarização do solo. Summa Phytopathologica 20:315. 1994.

TAKATSU, A. \& LOPES, C.A. Murcha-bacteriana em hortaliças: avanços científicos e perspectivas de controle. Horticultura Brasileira 15:170-177. 1997.

TAVARES, L.A., MICHEREFF, S.J., SOUZA, R.M. \& MARIANO, R.L.R. Análise de solo para detecção de riscos de infecção de tomateiro por Ralstonia solanacearum. Summa Phytopathologica 26:311-316. 2000.

YABUUCHI, E., KOSAKO, Y., YANO, I., HOTTA, H. \& NISHIUCHII, Y. Transfer of two Burkholderia and an Alcaligenes species to Ralstonia gen. nov.: proposal of Ralstonia picketii (Ralston, Palleroni and Doudoroff, 1973) comb. nov., Ralstonia solanacearum (Smith 1896) comb. nov. and Ralstonia eutropha (Davis 1969) comb. nov. Microbiology and Immunology 39:897904. 1995. 